\title{
Morfologi Bahasa Bali Aga Dialek Sembiran, di Kecamatan Tejakula, Kabupaten Buleleng
}

\author{
${ }^{1}$ Putu Evi Wahyu Citrawati, ${ }^{2}$ I Wayan Teguh, ${ }^{3}$ Putu N. Widarsini, ${ }^{4}$ Gede Eka Wahyu \\ Universitas Udayana, Indonesia \\ ${ }^{1}$ eviwahyu78@gmail.com \\ 2wayanteguh38@yahoo.co.id \\ ${ }^{3}$ n widarsini@unud.ac.id \\ ${ }^{4}$ eka.stpbispb14@gmail.com
}

\begin{abstract}
Abstrak
Bahasa Bali memiliki dua dialek utama, yaitu dialek Bali Dataran (DBD) dan dialek Bali Aga (DBA). DBD digunakan di daerah dataran Pulau Bali termasuk daerah perkotaan seperti Kota Denpasar, dan Kabupaten Badung. Sebaliknya DBA biasanya digunakan oleh masyarakat yang ada di daerah pegunungan, terutama daerah pegunungan Kintamani, Buleleng, Pulau Nusa Penida, dan Karangasem.

Desa Sembiran merupakan salah satu desa Bali Aga yang ada di Bali. Desa Sembiran terletak di Desa Sembiran, Kecamatan Tejakula, Kabupaten Buleleng. Seperti kebanyakan bahasa Bali Aga, bahasa Bali Aga dialek Sembiran sangat berbeda dengan dialek bahasa Bali dataran atau yang lazim disebut dengan bahasa Bali Kapara. Dialek bahasa Bali Aga memiliki struktur dan fungsi bahasa tersendiri yang berbeda jauh dengan bahasa Bali Daratan.

Perbedaan antara DBD dan DBA terlihat dari (1) variasi kosakata, (2) fonologi (termasuk pendistribusian bunyi vokal), (3) anggah ungguhing basa (bahasa halus dan bahasa kasar), serta (4) kosakata (Bawa, 1983). Yang paling jelas perbedaannya adalah pada dialek yang dipergunakan oleh masyarakat penggunanya. Sekadar diketahui bahwa, dalam DBA tidak dikenal adanya bahasa halus, tetapi yang ada hanya bahasa kasar.
\end{abstract}

Kata Kunci: Dialek, morfologi bahasa Bali, bahasa Bali Aga.

\begin{abstract}
Bahasa Bali has two main dialects, namely the Bali Dataran dialect (DBD), and the Bali Aga dialect (DBA). The DBD is used in the flat areas of Bali including urban areas such as Denpasar City, and Badung Regency. Whereas DBA is usually used by the community who live in mountainous areas, especially the areas of Kintamani, Singaraja, Nusa Penida Island, and Karangasem mountain.

Sembiran Village is one of the Bali Aga villages in Bali. Sembiran Village is located in Tejakula District, Buleleng Regency. As other Bali Aga languages, the Bali Aga dialect in Sembiran is extremely distinguish from the Bali Dataran dialect or commonly is called the bahasa Bali Kapara. The Bali Aga dialect has its own language structure and function that is different from the bahasa Bali Dataran.

The difference between DBD and DBA can be seen from (1) variety in vocabulary, (2) phonology (including vowel distribution), (3) anggah ungguhing basa (politness and
\end{abstract}


LINGUISTIKA, SEPTEMBER 2019

p-ISSN: 0854-9613

Vol. 26. No. 2

impolitness), and (4) vocabulary (Bawa, 1983). The most obvious difference is in the dialect that used by the user. It is only known that, in the DBA, there is no politness, its only impolitness.

This study focus on the morphological forms of the dialect Bali Aga in Sembiran village, it is include prefix, infix, suffix, confix, reduplication and other morphological processes. Moreover, it also discusses the meaning of the Bali Aga language, especially the Sembiran dialect.

This study use referral method in data collection, with advanced techniques in the form of note-taking techniques. Then after the data is recorded on the corpus data. Distributional method is used in analyzing data, which are working within the scope of the language itself without linking with things outside. In the final stage is the technique of presenting the results of data analysis using two methods namely formal and informal methods.

Keyword: dialect, Balinese morphology, bahasa Bali Aga 


\section{Pendahuluan}

Bahasa Bali (bB) merupakan subkelompok bahasa Austronesia, yang digunakan oleh masyarakat Bali sebagai bahasa Ibu, dengan jumlah penutur yang aktif kurang lebih sebanyak tiga juta orang. Bahasa Bali tidak hanya digunakan oleh masyarakat Bali yang mendiami wilayah dataran, tetapi juga digunakan oleh masyarakat Kepulauan Nusa Penida. Selain digunakan oleh masyarakat Bali yang ada di Pulau Bali, bahasa Bali juga banyak ditemukan di wilayah lain di Indonesia, seperti di Sumatra, Jawa, Lombok, Kalimantan, dan Sulawesi. terutama digunakan oleh warga Hindu di daerah transmigrasi.

Secara geografis, bahasa Bali dibagi menjadi dua dialek yaitu dialek Bali Daratan (DBA), dan dialek Bali Aga. (Bawa, 1983:394). Dialek Bali Dataran digunakan oleh masyarakat di wilayah dataran Pulau Bali seperti selatan atau daerah pesisir Pulau Bali, sedangkan dialek Bali Aga digunakan oleh masyarakat Bali yang mendiami wilayah pegunungan.

Dialek bahasa Bali Aga dan dialek bahasa Bali dataran cukup berbeda. Perbedaan ini terlihat dari segi (1) variasi kosakata, (2) dari segi fonologi (pendistribusian bunyi vokal), (3) anggah ungguhing basa (bahasa halus dan bahasa kasar), serta bentuk kosakata (Bawa, 1983). Yang paling jelas adalah perbedaan dialek antara penutur bahasa Bali Aga dan penutur bahasa Bali Dataran. Selain perbedaan dialek, perbedaan adat istiadat, dan budaya juga sangat kental.

Dialek Bali Aga dikelompokkan ke dalam tiga daerah pemukiman (Bawa, 1983:394). Pertama, DBA yang digunakan oleh kelompok masyarakat timur Pulau Bali yang meliputi wilayah Kabupaten Karangasem (Tenganan) sejumlah wilayah di Kecamatan Kintamani, Bangli (sekitar Danau Batur), DBA yang digunakan oleh masyarakat Nusa Penida di Kabupaten Klungkung, dan sebagian wilayah Buleleng Timur. Gabungan masyarakat penutur DBA di wilayah Kecamatan Kintamani dan wilayah Buleleng timur disebut dengan masyarakat Gebog Domas. Kedua, DBA yang digunakan oleh masyarakat yang berada di wilayah pegunungan Badung Utara, seperti wilayah Pelaga, Tihingan, dan Seminyak. Ketiga, DBA yang dipergunakan oleh masyarakat bagian barat Pulau Bali, seperti Kabupaten Tabanan yang meliputi wilayah Kecamatan Pupuan (Pujungan), wilayah Kecamatan Penebel ( Desa Wongaya), dan sebagian wilayah Buleleng Barat, seperti Desa Bantiran, Desa Sepang, Padawa yang berada di Kecamatan Busungbiu (Riana, 1995:3).

Salah satu daerah yang termasuk ke dalam DBA pada kelompok timur adalah Desa Sembiran. Dialek Bali Aga Sembiran (DBAS) digunakan secara luas oleh masyarakat penutur asli Desa Sembiran. Dialek ini digunakan oleh kurang lebih 4.883 penutur yang mendiami wilayah desa tersebut. Desa Sembiran merupakan salah satu desa Bali Aga (kuno) yang terletak di Kecamatan Tejakula, Kabupaten Buleleng. Berdasarkan data monografi desa dan kelurahan pada tahun 2017, desa ini terbagi ke dalam sepuluh banjar adat, yaitu Banjar Desa, Lagondi, Jangotan, Dukuh, Pohya, Bujangga, Bukit Seni, Panggung, Pramboan, dan Banjar Anyar. Kesepuluh banjar adat ini dikelompokkan lagi ke dalam enam banjar dinas, yaitu Dusun Kangin, Dusun Kauh, Bukit Seni, Dusun Panggung, Dusun Pramboan, dan Dusun Anyar.

\section{Teori \& Metodologi}

Penelitian ini menggunakan metode observasi langsung, yaitu mengamati fenomenafenomena yang diselidiki (Hadi, 1990:136). Kemudian dibantu juga dengan metode wawancara (Hadi, 1990:193).

Untuk menunjang analisis data, penelitian ini menggunakan teori morfologi yang dikembangkan oleh Chaer (2015) dan Ramlan (2009). Secara etimologi, morfologi berasal dari kata morf yang berarti bentuk, sedangkan logi berarti ilmu. Jadi, jika diartikan bahwa morfologi merupakan ilmu yang mempelajari bentuk kata. Ramlan (2009:21) mengatakan morfologi adalah bagian dari ilmu bahasa yang membicarakan atau mempelajari seluk-beluk bentuk kata serta pengaruh perubahan-perubahan bentuk kata 
terhadap golongan dan arti kata atau dengan kata lain dapat dikatakan bahwa morfologi mempelajari seluk-beluk bentuk kata serta fungsi perubahan-perubahan bentuk kata itu, baik fungsi gramatik maupun fungsi semantik (Dhanawaty dkk 2017: 47-48).

Ramlan (2009:51—82) membagi proses morfologis menjadi tiga, yaitu : (1) afiksasi, (2) reduplikasi, dan (3) komposisi. Akan tetapi, dalam penelitian ini komposisi tidak ditemukan.

\section{Temuan \& Pembahasan}

\section{Afiksasi}

Afiksasi merupakan proses pembubuhan afiks pada sebuah dasar atau bentuk dasar. Proses ini melibatkan unsur-unsur dasar atau bentuk dasar, afiks, dan makna gramatikal yang dihasilkan. Kridalaksana dalam Kamus Linguistik (2001) mengatakan bahwa afiks merupakan bentuk terikat yang bila ditambahkan pada bentuk lain, akan mengubah makna gramatikalnya.

Afiks dalam bahasa Indonesia, jika dilihat dari posisi melekat pada bentuk dasar dibedakan menjadi prefiks, infiks, sufiks, konfiks, dan sirkumfiks.

1. Anita menulis surat.

Kata menulis, merupakan bentuk prefiks mebertemu dengan kata dasar tulis. Huruf $t$ pada kata tulis $\rightarrow$ nulis $\rightarrow$ menulis

2. Ayah meniup seruling. Kata seruling berasal dari kata dasar suling mendapat infiks -er $\rightarrow$ seruling.

3. Tolong ambilkan saya buku itu. Kata ambilkan terdiri atas kata dasar ambil dan akhiran/sufiks kan.

4. Sejak kematian Ibunya dia selalu menangis. Kematian berasal dari kata dasar mati dan mendapat konfiks ke-/-an $\rightarrow$ kematian.

Pada bahasa Bali Aga Dialek Sembiran ditemukan beberapa afiks, yaitu, sebagai berikut.

1. Ngara m-orah-an jah ken beli, patuh-in cahhi beli.

“ Tak bilang-bilang sama kakak, kamu samain aku"

2. Iyaa $m$-(b)-eli tempelan

"Dia membeli tempelan"
3. Memme iyya $m$-(b)oreh, kadda iyya gelem.

"Ibu nya menggunakan param karena ia sakit"

4. Gunung Batur-e ma-letus m-(p)esu-ang lahar

"Gunung Batur meletus mengeluarkan lahar"

5. Padi-ne ento jani lakar tebuk-ka, nto kadda jemuh-ha di natah-e.

"Padi itu mau ditumbuknya, Oleh karena itu, dijemurnya di halaman"

6. Siyyap-e teguh kiching

"Ayam digigit anjing"

7. Nengah ny-(s)ugi-n-in muwan-n-a-nn-e aji yeh anget

"Nengah membasuhi mukanya dengan air hangat"

8. $\quad N$-jekauh-ang masih alih I Tingeh

"Ke barat laut juga kucari I Tingeh"

9. I Bawang $n$-(t)akon-ang sahhang "Si Bawang menanyakan kayu bakar"

10. Ngelaut Pan Angklung Gadang ka-silemang di yeh-e kanti slegak-slegak

"Lalu Pan Angklung Gadang ditenggelamkan di air sampai terengahengah"

11. Baju-n-a-nn-e pejuhhun-in kedis

"Bajunya diberaki burung'

12. Okke ngiddih-in nanang-a-nn-e Bangsing jagung

"Aku/saya memintai Pak Bangsing Jagung"

13. Ba kento cangkling-nga, tekep-in-nya aji guhungan

"Sudah begitu diikatnya, ditutupi menggunakan keranjang"

14. I Bawang $n$-(t)ulung-in I Rangsasa $n g$ eleng-in kutu

"I Bawang membantu raksasa mencari kutu"

15. Ipah-he nto $n$-(t)ulung-in beli ng-addep satuh

"Iparku itu membantu kakak menjual satuh"

Berdasarkan data $1-15$, diperoleh tiga jenis proses morfologis, yaitu prefiks, sufiks, dan 
konfiks. Pada data 1 dan 3 merupakan bentuk prefiks pada DBAS berupa awalan $\{m a-\}$. Pada contoh 1 dan 4 awalan $\{m a-\}$ berfungsi sebagai verba intranstif yang menyatakan keadaan dan perbuatan, yang ditunjukkan dengan kata $\{m$ orah-an\}, dan $\{$ ma-letus $\}$, sedangkan afiks pada contoh 2 dan 3 berfungsi melakukan suatu tindakan (kegiatan). Data 5a termasuk ke dalam jenis morfologis berupa sufiks $\{-k a\}$ yang berbentuk pasif, sedangkan pada data $5 \mathrm{~b}$ termasuk sufiks $\{-h a\}$ pasif. Bentuk pasif ditunjukkan dengan kata tebuk-ka dan jemuh-ha yang berarti ditumbuknya, dan dijemurnya.

Data 6 yaitu siyyap-e "ayamnya" merupakan bentuk sufiks yang ditandai dengan kata $\{-e\}$ yang berarti kepunyaanya/miliknya. Pada contoh ini terdapat bentuk sufiks yang berupa kata dasar pasif. Data 7-9 merupakan bentuk konfiks nasal $\{-n\}$ kemudian mendapat akhiran $\{$-ang $\}$. Data 10 termasuk bentuk konfiks $\{k a-a n g\}$ yang berbentuk pasif. Data $11-12$ termasuk ke dalam konfiks $\{-n\} /$ nasal dengan akhiran -in. Data 13 termasuk bentuk sufiks \{nga $\}$ dan sufiks $\{$-in $\}$ pasif. Data $14-15$ termasuk bentuk konfiks $\{-n\}$ dengan akhiran $\{-$ in \}, tetapi pada contoh tersebut terdapat pelesapan huruf /t/ dengan bentuk dasar yang berawalan nasal.

\section{Reduplikasi}

Bentuk lain yang ditemukan dalam DBAS adalah reduplikasi. Seperti yang telah dijelaskan pada bab II, reduplikasi adalah bentuk pengulangan satuan gramatik, baik seluruhnya maupun sebagian, baik dengan variasi fonem maupun tidak. Hasil pengulanganya disebut dengan kata ulang, sedangkan satuan yang diulang merupakan bentuk dasar (Ramlan, 2009:63). Ada empat jenis reduplikasi, yaitu reduplikasi/pengulangan seluruh, pengulangan sebagian, pengulangan yang berkombinasi dengan proses pembubuhan afiks, dan pengulangan dengan perubahan fonem.

16. Suhud ndahar nutur-nutur ba ja roang-e "Selesai makan bercerita-cerita dengan teman"
17. Amun adda tuak ditu barengin ba nginemnginem

"Kalau ada yang minum tuak di sana ikut minum-minum"

18. Iccang saha-saha di pedemanne madak okke ngelah pannak meninya

"Aku berdoa dari tempat tidur semoga punya anak laki-laki"

19. Matane tamplak undur-undur

"Matanya kemasukan serangga malam".

20. Iyya kenyar-kenyir dogen.

"Dia senyum-senyum saja"

Jika dilihat dari data $16-20$ di atas, dapat dianalisis jenis reduplikasi yang terdapat dalam DBAS. Data 16 merupakan bentuk reduplikasi utuh, karena kata dasar yang diulang adalah nutur 'bercerita' dan diulang secara utuh sehingga menjadi 'nutur-nutur' bercerita-cerita. Kata dasar nutur, jika diucapkan sekali tetap memiliki arti yaitu bercerita. Data 17 di atas merupakan bentuk reduplikasi utuh, dengan bentuk dasar nginem 'minum'. Begitu juga dengan data 18, kata dasar saha jika diucapkan sekali tidak memiliki arti. Jika diucapkan saha-saha memiliki arti, sehingga bentuk reduplikasi pada data 18 adalah reduplikasi semu. Reduplikasi semu juga ditemukan pada data 19, yaitu undur-undur 'binatang malam/serangga malam'. Jika hanya diucapkan sekali undur dalam bahasa Bali tidak memiliki arti, namun jika diucapkan utuh kata undur-undur memiliki arti. Data terakhir, yaitu data 20 termasuk ke dalam reduplikasi berubah bunyi karena kata kenyar-kenyir mengalami perubahan fonem, yaitu dari fonem /a/ pada bentuk pertama, kemudian berubah fonem menjadi fonem /i/ pada bentuk kedua. Jika hanya diucapkan sekali, kata kenyar dalam bahasa Bali tidak memiliki arti, begitu juga kata kedua kenyir. Jika kedua kata tersebut diucapkan secara terpisah tidak memiliki arti/makna. Jika kedua bentuk kata tersebut dirangkai menjadi kenyarkenyir memiliki arti senyum-senyum. Dalam bahasa Bali ini termasuk bentuk reduplikasi berubah bunyi. 


\section{Simpulan}

Pada bahasa Bali Dialek Sembiran ditemukan beberapa proses morfologis, baik berupa afiksasi (prefiks, sufiks, dan konfiks) serta reduplikasi. Prefiks pada DBAS berupa awalan $\{m a-\}$, berfungsi sebagai pembentuk verba intranstif yang menyatakan keadaan dan perbuatan, yang ditunjukkan dengan kata $\{m-$ orah-an\}, dan $\{$ ma-letus $\}$. Sufiks $\{-k a\}$ dan sufiks $\{-h a\}$ berbentuk pasif, ditunjukkan dengan kata \{tebuk-ka\} dan jemuh-ha.

Pada bentuk reduplikasi DBAS ditemukan tiga jenis reduplikasi, yaitu (1) reduplikasi utuh yang ditunjukkan dengan kata \{nutur-nutur\}, (2) reduplikasi semu \{undurundur\}, dan (3) reduplikasi perubahan fonem \{kenyar-kenyir $\}$.

\section{Daftar Pustaka}

Arifin, Zaenal dkk. 2009. Morfologi: Bentuk, Makna, dan Fungsi. Jakarta : Grasindo.

Bawa, I Wayan dkk. 1983. "Bahasa Bali di Daerah Bali: Sebuah Pemerian Geografi Dialek". Jakarta: Disertasi Fakultas Sastra UI.

Budiastra, I Putu dan I Wayan Wardha. 1989. "Babad Kayu Selem". Denpasar: Museum Bali.

Chaer, Abdul. 2015. Morfologi Bahasa Indonesia (Pendekatan Proses). Jakarta: Rineka Cipta

Dhanawaty dkk. 2017. Pengantar Linguistik Umum. Denpasar : Pustaka Larasan.

Hadi, Sutrisno. 1990. Metodologi Research 2. Yogyakarta: Andi Offset.

Kridalaksana, Harimurti. 1982 Kamus Linguistik. Jakarta: Gramedia.

Laksana, Darma. 1977. Morfologi Bahasa Bali Dialek Nusa Penida. Tesis. Denpasar

Sedeng, I Nyoman. 2010. Morfosintaksis Bahasa Bali Dialek Sembiran. Analisis Tatabahasa Peran dan Acuan. Denpasar: Udayana University Press.

Sudaryanto. 2015. Metode dan Teknik Analisis Bahasa. Yogyakarta: Sanata Dharma University Press.
Tarigan, Henry Guntur. 1985. Pengajaran Morfologi. Bandung: Angkasa. 